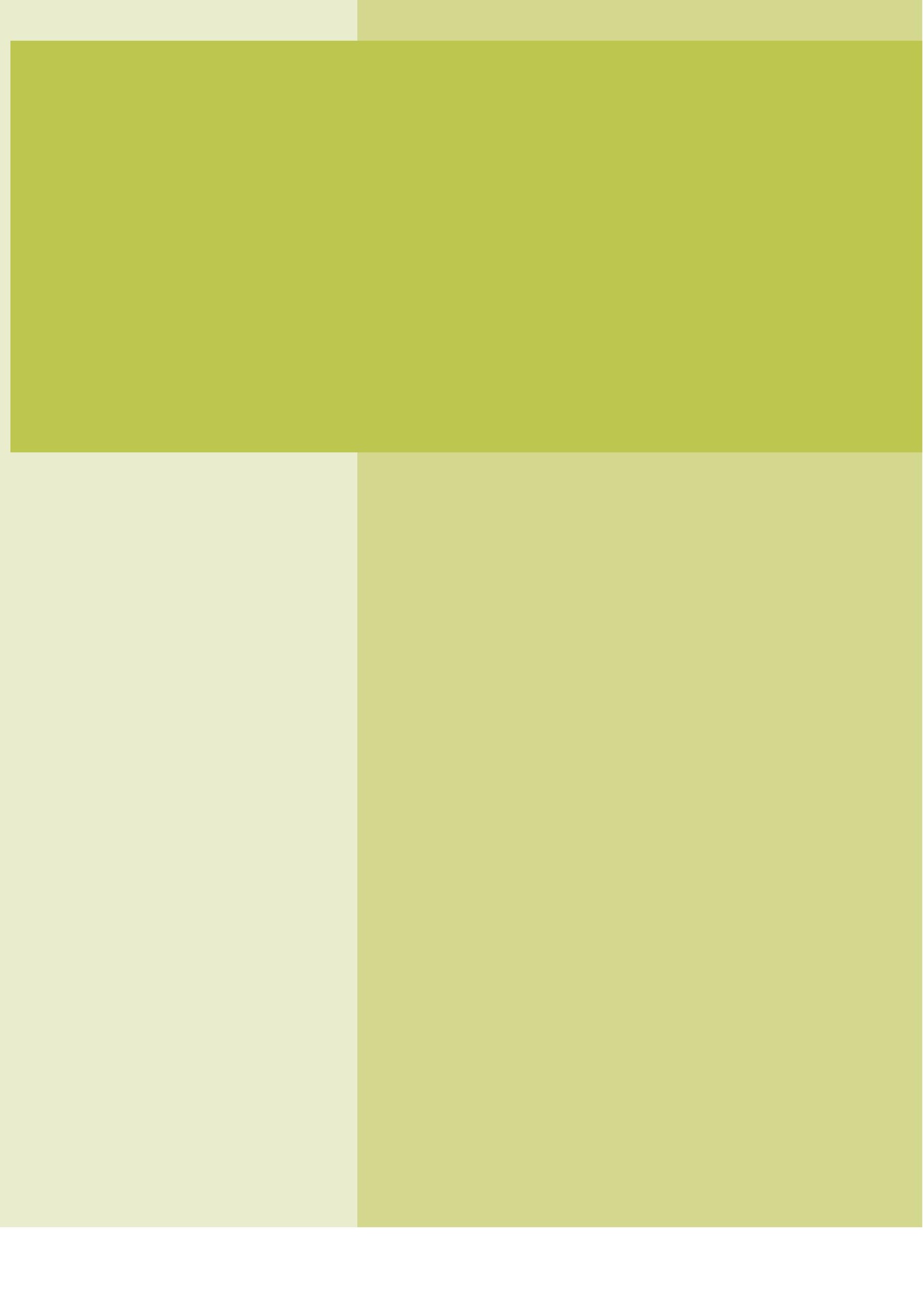




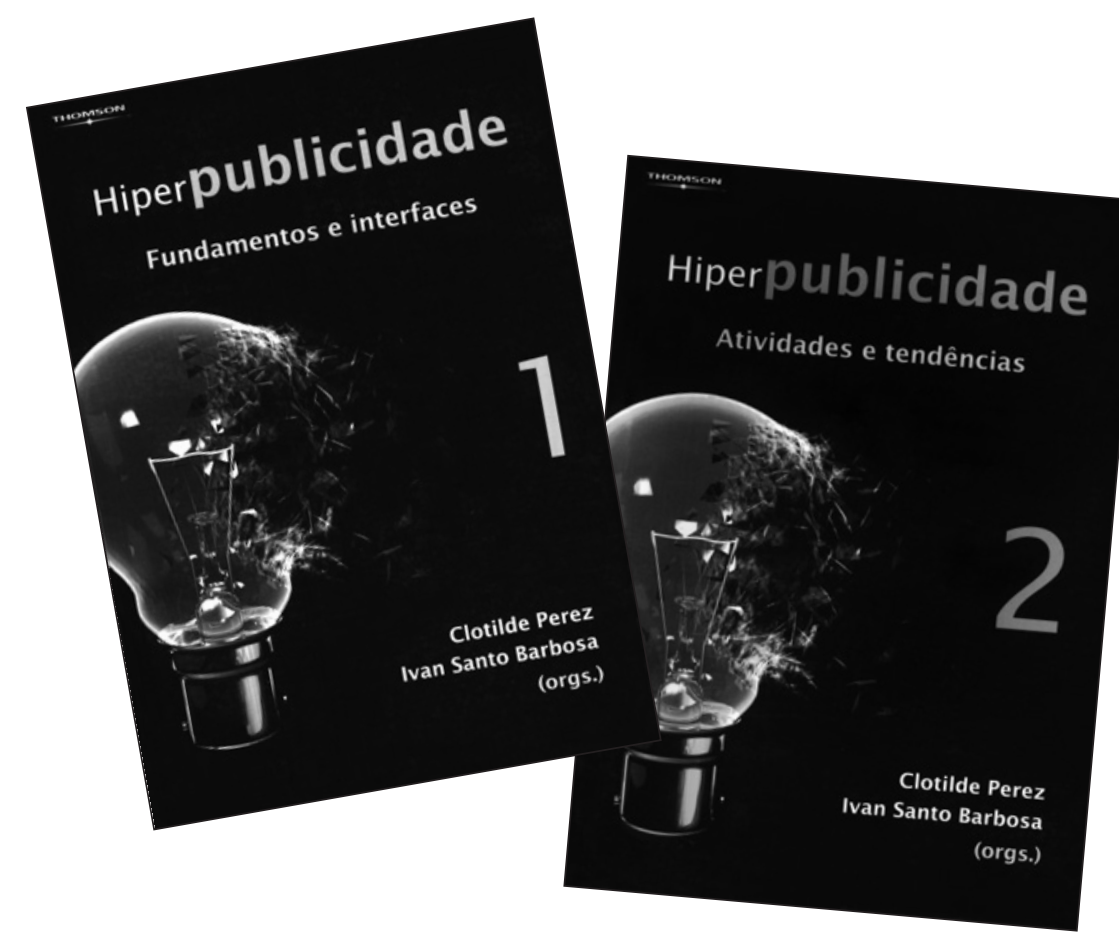

Clotilde Perez e Ivan Santo Barbosa (orgs.)

Hiperpublicidade: fundamentos

e interfaces vol. 1 e

Hiperpublicidade: atividades

e tendências vol. 2

\section{São Paulo:}

Thomson, 2007 (vol. 1) e 2008 (vol. 2)

vol. 1: 431 páginas

vol. 2: 516 páginas

\section{Kleber Markus}

- Doutor e Mestre em Ciências da Comunicação pela Escola de Comunicações e Artes da Universidade de São Paulo (ECA-USP)

- Professor Titular da Universidade Metodista de São Paulo (Umesp) e do Programa de Pós-Graduação em nível de Especialização da ECA-USP

•kmarkus@uol.com.br 


\section{0 lugar do vazio}

rovavelmente, não há um pesquisador que atue na área da comunicação mercado-

lógica que não tenha sido convidado a esclarecer, "definitivamente", o que é publicidade. Vivemos num mundo repleto de neologismos e estrangeirismos, frases feitas, novos nomes-casca para tradicionais conceitos, e palestrantes que procuram explicar tsunamis-hollywoodianos, em detrimento da análise sistêmica da Tábua das Marés, responsabilidade dos acadêmicos.

Nesse sentido, Hiperpublicidade, obra com 947 páginas divididas em dois volumes, publicada pela Thomson, 2007, e que teve a competente organização do Prof. Dr. Ivan Santo Barbosa e da Prof ${ }^{a}$. Dr. ${ }^{\text {a }}$ Clotilde Perez, dá substância às discussões mais complexas sobre o fenômeno intrincado da publicidade.

Desde o prefácio, ácido e primoroso, de Massimo Canevacci, somos convidados a perder o foco, uma vez que o novo target, agora em movimento, representa uma armadilha à nossa lenta artilharia, construída sob a égide da Revolução Industrial. Em outras palavras, atingir o target pode significar atingir apenas as sombras e o vazio dos objetos que se deslocam segundo novas orientações etnográficas.

Abordando, no Volume I, os fundamentos da publicidade, a obra forma bases metodológicas para a ampla discussão que está por vir, baseada nas reflexões sobre a Teoria Sistêmica e a Teoria da Linguagem. Na seqüência, a perspectiva do ensino da publicidade passa por um meticuloso resgate histórico das escolas de publicidade e propaganda e pela difícil relação entre a educação e o mercado. O fio interdisciplinar prossegue com uma interessante discussão que se propõe a investigar as entranhas da publicidade, por meio dos seus múltiplos aspectos contemporâneos, questionando seu valor como ciência, arte ou, até mesmo, como fruto de habilidades pessoais desenvolvidas com base num conjunto de técnicas empíricas, em oposição à episteme do stricto sensu.

Oferecendo já massa crítica suficiente para reflexões, apresenta, ainda, aos leitores uma importantíssima retrospectiva da história da propaganda brasileira, com inúmeras peças que marcaram essa trajetória, e o concomitante alinhamento (ou desalinhamento) dos veículos que iriam transmitir criativas mensagens mercadológicas, codificadas pelas agências que emprestavam ao setor o glamour de inesquecíveis campanhas.

Evidencia-se, a partir desse ponto, o caráter abrangente e de profundidade da obra. $\mathrm{O}$ anunciante, muito mais do que o "pagador das contas", entra em cena como elemento-chave, de onde emanam as necessidades de se atingirem metas de vendas, pro- 
piciando ao leitor a compreensão crua de que a comunicação mercadológica não existe por si só, em um mundo à parte, no qual premiações e festivais poderiam proporcionar a falsa e desastrosa percepção de que a publicidade teria, como atividade fim, que acariciar egos de criativos geniais e ensimesmados.

O aprofundamento prossegue com talento no perigoso terreno em que se discute a origem dos termos publicidade e propaganda, caminhando para abordagens sobre comportamento do consumo, integração da publicidade no marketing mix, com a competente análise da visão integrada de marketing, desenvolvida por meio do modelo ampliado dos Inputs, Throughputs e Outputs.

Uma explanação holística e integrada sobre serviços, marketing de relacionamento, marketing político, semiótica e gestão de marcas, histórico das agências de comunicação (Relações Públicas) e patrocínio fecha o primeiro volume, colocando a obra, de fato, como ícone bibliográfico a ser largamente utilizado por profissionais de mercado e pesquisadores dessa área tão carente de abordagens menos simplistas.

O Volume II, por sua vez, apresenta uma inédita composição de textos integrados, focando o exercício da publicidade e suas tendências. A organização das agências de publicidade e suas diferentes estruturas administrativas são abordadas com base em pressupostos teóricos, não poupando a atividade criativa da necessidade de se estabelecer em um ambiente planejado e organizado, buscando eficácia e eficiência, caminho de mão única nas empresas contemporâneas.

O planejamento publicitário, aliado à pesquisa de mercado, é apresentado de forma racional, perpassando pela apresentação de diferentes tipos de pesquisas, testes de conceitos, de produtos e de embalagens, para que, com a indispensável contribuição da semiótica, possa garantir o cumprimento das metas dos anunciantes, após, metodologicamente, terem sido investigados os movimentos do consumidor.

Neste bojo, fica fácil compreender a grande transformação nos caminhos da direção de arte, momento em que o efeito decorativo e simples da criação transforma-se em poderosa estratégia, com o avanço concomitante da intertextualidade e com a expansão definitiva da fotografia em fotopublicidade, em que não se admitem mais curiosos.

Finalmente, a mídia é retratada desde seus conceitos mais fundamentais, para brindar o leitor com algo que poderíamos chamar de transmídia, representada pela reação dos meios convencionais aos alvos móveis, na composição pós-geográfica e pósurbana das paisagens-fluxo de nosso século.

Trabalho árduo e bem-vindo, viabilizado pelos co-autores, pesquisadores da ECA-USP, que representam valiosos anticorpos à bíblica Torre de Babel, sustentáculo, ainda, de nossa publicidade. 



\section{Outras publicações de referência}
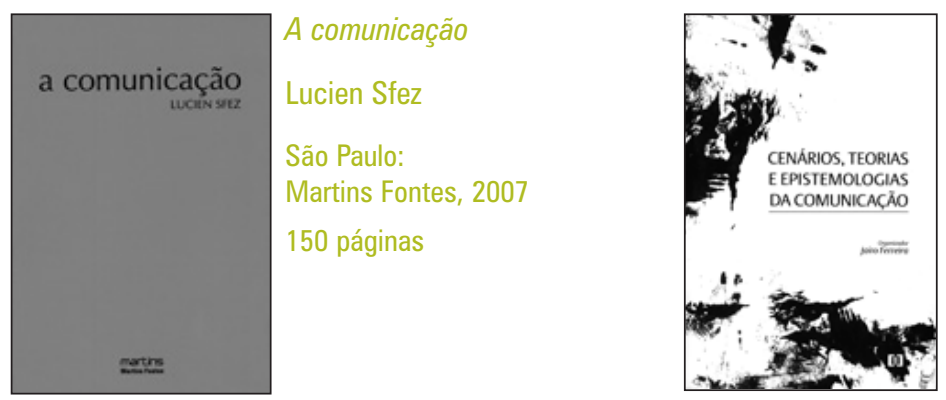

Cenários, teorias

e epistemologias

da comunicacão

Jairo Ferreira (org.)

Rio de Janeiro:

E-papers, 2007

248 páginas

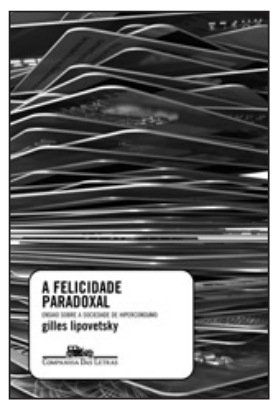

A Felicidade paradoxal: ensaio sobre a sociedade de hiperconsumo

Gilles Lipovetsky

São Paulo:

Companhia das Letras, 2007

402 páginas

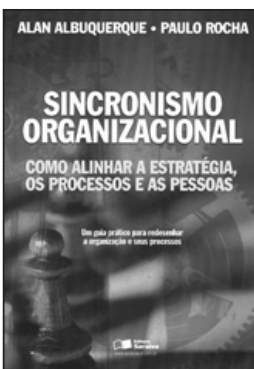

Sincronismo organizacional: como alinhar a estratégia,

os processos e as pessoas

Alan Albuquerque e

Paulo Rocha

São Paulo:

Editora Saraiva, 2007

166 páginas

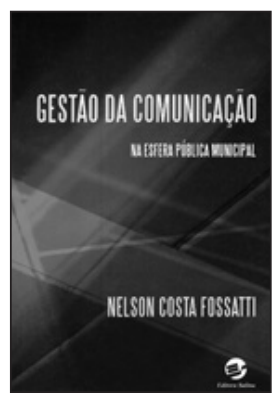

Gestão da comunicação:

na esfera pública municipal

Nelson Costa Fossatti

Porto Alegre, RS:

Editora Sulina, 2006

207 páginas 